of supply and demand but on account of governmental measures of extrusion adopted in Eastern Europe.

I am, Sirs, yours faithfully,

Chelsea Embankment, s.W.

W. EVANS. GORDON.

\section{THE URBAN HOSPITAL TREATMENT OF TUBERCULOSIS.}

To the Editors of THE LANOWT.

SIRS, - The report on the urban hospital treatment of tuberculosis by the committee appointed by the Society for the Study of Disease in Children to inquire into the matter and report to them is still under consideration by that body, and its publication in THE LANCET of Dec. 5th, p. 1590, was owing to an unfortunate oversight. As this report is still sub judioe its discussion at the present moment would be premature. - I am, Sirs, yours faithfully,

George Carpenter,

Welbeck-street, Cavendish-square, W., Dec. 7th, 1903.

\section{THE MORTALITY AFTER OPERATIONS FOR STRANGULATED UMBILICAL HERNIA.}

To the Editors of THE LANCET.

SIRS, - I shall be glad if any of your readers can give me a reference to any statistics with regard to this subject. I have been unable to find any definite information but that it is unexpectedly high I believe.

Hove, Dec. 3rd, 1903.

I am, Sirs, yours faithfully, ARTHUR H. BUCK.

\section{THE PHOSPHATES AND UREA OF URINE.}

\section{To the Editors of THE LANCET.}

SIRS,-I shall be obliged if you will give me space for a somewhat belated acknowledgment of the communications from Dr. H. Harper, Dr. A. W. Gilchrist, and others, in THE LANCET of the latter end of 1902, and January of this year, referring to a paper of mine on the above subject. ${ }^{1}$ These letters appeared at a period when serious illness prevented me from attending to anything, and I have only recently found an opportunity of looking through the back numbers of your journal.

To remove misconception (for I think there was some, partly owing perhaps to the results of the analyses having been tabulated, for the sake of brevity, so that the figures yielded by very different pathological samples were in juxtaposition), I should like to state, chiefly in reply to Dr. Gilchrist :1. That I never thought to "establish an analogy" between the diseases. In one not a medical man $I$ should think this presumptuous 2. As a scientific chemist I have long known the desirability that analyses of urine should represent the collective fluid excreted during 24 hours. But for the analyst and if $\mathrm{I}$ mistake not, for the medical man also, this is very often impracticable. The former, at all events, has to work with just what is submitted to him, frequently by the medical adviser, who cannot help himself. 3. Professing to no knowledge of medicine, I certainly did not intend it to appear as if I had had the temerity to make any precise comparison of the composition of tuberculous urine with that of the fluid from glycosuria or with other samples of urine from similar cases. No data were at my command for this sort of comparison, which was left, of course, to medical men. I sent these analyses, such as they were, to THE LANCET on the chance that they might be of some service or interest to my medical brethren; but I was far from wishing to seem to attach to them undue importance and was particular in giving what information I possessed, as to times, \&c., so as to show clearly that the samples were not representative of the entire 24 hours' excretion. Any remarks - they could hardly be called conclusions-were extremely guarded, and confined to comparisons of the most general kind, not with analyses of other pathological urines, but with such statements regarding the limits of composition of normal urine as are to be found in ordinary works of reference-by Halliburton, Hammarsten, Allen, Pearmain and Moor, and others; and referred only to the actual samples, as they were received. I do not at al claim infallibility for the remarks in question. At the worst, if the paper had no other use, the figures recorded such analytical results as may be yielded in particular circumstances and by limited samples, representing only part of the 24 hours - such as medical practitioners must often be forced to be content with. 4. As far as my own imperfect opportunities permitted me to judge, I was under the impression that there were not very many readily accessible analyses, at all events as full as that of the tuberculous sample, and personally I had never seen any published analysis of urine from a case of tuberole of the bladder. For my own information. I should be grateful for references to such analyses, and interested to know whether the figures are simular to, or different from, those yielded in other cases of tuberculosis, as of the lungs; also whether the "graph" in Dr. Gilchrist's communication represented the results from one sample of tuberculous urine or the mean of several.

Lastly, the cautiously chosen title of the paper, "Observed Variations," \&c.. was changed in the later communications to "The Low Phosphates and Urea," \&c. I must disclaim responsibility for this. My own use (in the paper) of the expression, "low phosphates" related solely to the particular set of analyses and to the actual specimens of urine received, imperfectly representative as they may have been. This was without any universal application or generalisation, such as the latter title might imply: I intended none.-I am, Sirs, yours faithfully,

EDWy G Clayton, F.I.C., F.C.S.

Holborn Viaduct, E.C., Nov. 30th, 1903.

\section{RADIUM AND THE BACILLUS TYPHOSUS. To the Edutors of THE LANCET.}

SIRS,- The following experiences with bromide of radium upon cultures of the bacillus typhosus may be of interest to some of your readers. The cultures were of the usual kind, in agar, and were exposed to the rays of 50 milligrammes of the salt for periods varying from 15 minutes to 48 hours. The longer exposures were in the dark in order to eliminate any inhibitory effect of daylight upon the cultures. The tubes containing the cultures were at first placed horizontally above the radium at a distance of five centimetres but were afterwards allowed to rest in an upright position actually upon the mica cover of the box containing the radium, so that the culture received the full rays diverying from below upwards throughout its length. From each tube subcultures were afterwards taken without difficulty and so far as could be observed there seemed to be no inhibitory action upon the growth of the culture. Rather the contrary, for, in the opinion of more than one observer, examining the cultures under a high power, there seemed to be more activity in those cultures which had been subjected to the longer exposures, and in cultures which had been exposed, than in others of the same date which had not been exposed to the radium but had been simply excluded from daylight.

These experiences would seem to lead one in the direction of supposing the beneficial action of radium in certain cases to be that of stimulation of normal tissue rather than directly bactericidal. It is not easy to determine accurately the activity of a radium salt, but at a rough estimate the radium used in this instance is sufficiently strong to make its rays apparent upon the screen through a thickness of 15 coins, half-crowns and pennies. They pass easily therefore through the thickest part of a Cabaud gauge and in therapeutic use an application to the skin of five minutes produces redness and one of ten minutes a slight burn, appearing after two days. The cultures were kindly prepared for me in the laboratory of the Westminster Hospital.

I am, Sirs, yours faithfully,

Beaumont-street, W., Dec. 5th, $1903 . \quad$ R. BROWNE-CARTHEW.

\section{ST. JOHN'S HOUSE OF REST, MENTONE.} To the Editors of THE LANOET.

SIRS, - We are anxious through the medium of your journal to draw the attention of the members of the medical profession to the existence in Mentone of St. John's House of Rest which we believe to be little known to them. The institution, which was founded 25 years ago, is intendedifor 